\title{
Erratum to: Structural Information and Communication Complexity
}

\author{
Thomas Moscibroda ${ }^{1}$ and Adele A. Rescigno ${ }^{2}$ \\ 1 System Algorithms Research Group, Microsoft Research Asia, \\ No. 5, Dan Ling Street, 100080 Beijing, China \\ moscitho@microsoft.com \\ 2 Università di Salerno, Dipartimento di Informatica, \\ Via Ponte don Melillo, 84084 Fisciano, SA, Italy \\ arescigno@unisa.it
}

\section{Erratum to:}

\section{T. Moscibroda and A.A. Rescigno (Eds.) Structural Information and Communication Complexity} DOI: $10.1007 / 978-3-319-03578-9$

The book was inadvertently published with an incorrect name of the copyright holder. The name of the copyright holder for this book is: (c) Springer-Verlag Berlin Heidelberg. The book has been updated with the changes.

\footnotetext{
The updated original online version for this book can be found at DOI: 10.1007/978-3-319-03578-9

T. Moscibroda and A.A. Rescigno (Eds.): SIROCCO 2013, LNCS 8179, p. E1, 2013.

(C) Springer-Verlag Berlin Heidelberg 2017
} 